\title{
An evaluation of the diagnosis and treatment of chordoma
}

\author{
ROBERT P. KAMRIN, THE LATE JOHN N. POTANOS, AND J. LAWRENCE POOL \\ From the Department of Neurological Surgery, Columbia University \\ College of Physicians and Surgeons, and The Neurological Institute nf New York
}

Improved methods of diagnosis have indicated that chordoma more frequently affects the central nervous system than was previously suspected. For example, in a large neurosurgical service, one can now expect to see one or two cases a year. The world literature in 1960 , derived mostly from isolated case reports, mentioned 548 cases of chordoma in the following locations: 240 intracranial, 81 vertebral, and 227 sacrococcygeal (Forti and Venturini, 1960). Few large series, however, have been published from single institutions (Dahlin and MacCarty, 1952; Poppen and King, 1952; Congdon, 1952). This paper presents all histologically confirmed cases of chordoma, 30 in number, seen at the Columbia Presbyterian Medical Centre since 1927.

\section{MATERIAL}

The 30 cases of chordoma discussed in this report have all been histologically verified by biopsy and five have in addition been confirmed by necropsy. Sixteen of these cases were diagnosed on clinical grounds since 1950. After diagnosis, all these patients were treated by surgery and/or radiotherapy.

\section{DISTRIBUTION}

Chordomas are classified according to their origin from intracranial, vertebral, or sacrococcygeal sites. A separation of the intracranial group into those arising from the clivus and those arising elsewhere in the cranium, however, is not useful clinically because of the marked overlapping of symptoms.

Early reviews noted a preponderance of sacrococcygeal chordomas; more recent studies have shown chordomas to be equally divided between intracranial and sacrococcygeal locations (Faust, Gilmore, and Mudgett, 1944; Forti and Venturini, 1960; Zoltán and Fényes, 1960). The vertebral group accounts for only $15 \%$ of all these tumours, their distribution being cervical, lumbar, and thoracic in decreasing order of frequency. The median age of onset of symptoms is the middle thirties for intracranial chordoma and middle fifties for other chordomas. Males outnumber females 3 : 1 (Dahlin and MacCarty, 1952).

Our cases differ from other series in distribution, 16 being intracranial, nine vertebral (four cervical, one thoracic, four lumbar), and five sacrococcygeal. The age of onset varied from the post-pubertal years to the eighth decade (Table I). The age distribution

TABLE I

AGE AT ONSET OF SYMPTOMS

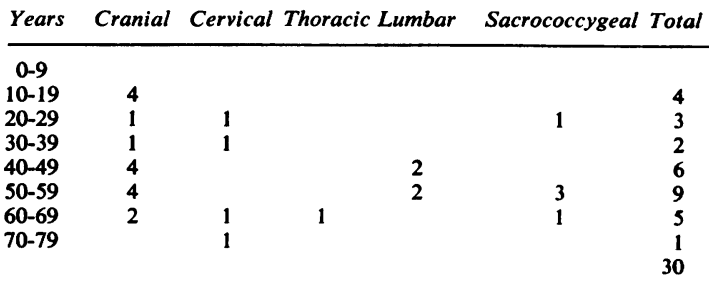

of the present series confirms that whereas vertebral and sacrococcygeal tumours most often appear after the age of 50 , it is not rare to find that chordomas become symptomatic in the second decade. This was also noted by Mabrey (1935) who found $13 \%$ of intracranial chordomas occurring before the age of 20 and $25 \%$ before age 30 years. The high incidence of chordoma in males was also noted in our series: 22 males and only eight females.

\section{CLINICAL COURSE}

INTRACRANIAL Symptoms were usually present for one year before the patient was admitted to hospital for study (Table II). The most frequent symptoms of onset were headache of a generalized nature and/or a visual disturbance. The most common visual complaint was diplopia although decreased visual acuity or ptosis have also been reported (Table III). 
TABLE II

LENGTH OF SURVIVAL AND THERAPY OF TUMOUR

\begin{tabular}{|c|c|c|c|}
\hline Tumour Site & $\begin{array}{l}\text { Survival from Onset of } \\
\text { Symptoms }\end{array}$ & $\begin{array}{l}\text { Survival from Start of } \\
\text { Therapy }\end{array}$ & Type and Amount of Therapy \\
\hline Intracranial & 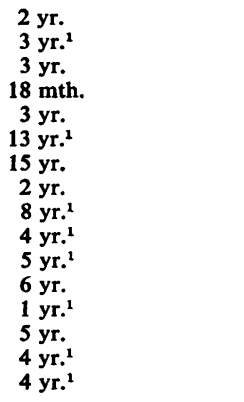 & $\begin{array}{l}4 \text { days } \\
2 \text { yr. } \\
2 \text { yr. } \\
6 \text { mth. } \\
1 \text { yr. } \\
11 \text { yr. } \\
14 \text { yr. } \\
1 \text { yr. } \\
7 \text { yr. } \\
2 \text { yr. } \\
4 \text { yr. } \\
5.5 \text { yr. } \\
6 \text { mth. } \\
4 \text { yr. } \\
2 \text { yr. } \\
2 \text { yr. }\end{array}$ & $\begin{array}{l}\text { Subtotal removal } \\
\text { Total removal, } 4,000 \mathrm{r} \text { tumour dose } \\
\text { Biopsy, } 3,600 \mathrm{r} \text { tumour dose } \\
\text { Subtotal removal, 5,000r tumour dose } \\
\text { Subtotal removal } \\
\text { Subtotal removal, } 16,000 \mathrm{r} \text { tumour dose } \\
\text { Biopsy, } 17,500 \mathrm{r} \text { tumour dose, radium, chemotherapy } \\
\text { Subtotal removal } \\
\text { Subtotal removal, } 9,000 \mathrm{r} \text { tumour dose } \\
\text { Subtotal removal, } 4,000 \mathrm{r} \text { tumour dose } \\
\text { Subtotal removal, } 4,800 \mathrm{r} \text { tumour dose } \\
\text { Biopsy, } 13,000 \mathrm{r} \text { tumour dose } \\
\text { Biopsy, } 6,000 \mathrm{r} \text { tumour dose } \\
\text { Biospy, 4,000r tumour dose } \\
\text { Biopsy, } 5,000 \mathrm{r} \text { tumour dose } \\
\text { Biopsy, } 4,000 \mathrm{r} \text { tumour dose, chemotherapy }\end{array}$ \\
\hline Cervical & $\begin{array}{r}9 \mathrm{yr}^{-} \\
3 \mathrm{yr}^{1} \\
17 \mathrm{yr}^{1} \\
4 \mathrm{yr}^{1}\end{array}$ & $\begin{array}{l}8 \mathrm{yr} . \\
2 \mathrm{yr} . \\
16 \mathrm{yr} \text {. } \\
2 \mathrm{yr} .\end{array}$ & $\begin{array}{l}\text { Biopsy, } 10,500 \text { tumour dose } \\
\text { Subtotal removal, } 4,200 \mathrm{r} \text { tumour dose } \\
\text { Subtotal removal } \\
\text { Biopsy, } 6,000 \mathrm{r} \text { tumour dose }\end{array}$ \\
\hline Thoracic & 3 yr. $^{1}$ & 2 yr. & Subtotal removal, 6,000r tumour dose \\
\hline Lumbar & $\begin{array}{r}2 \text { yr. }^{1} \\
8 \text { yr. }^{1} \\
14 \text { yr. }^{1} \\
4.5 \mathrm{yr}^{2}\end{array}$ & $\begin{array}{l}1 \mathrm{yr} . \\
4 \mathrm{yr} . \\
8 \mathrm{yr} . \\
4 \mathrm{yr} .\end{array}$ & $\begin{array}{l}\text { Subtotal removal, } 6,000 \text { r tumour dose } \\
\text { Subtotal removal, 5,000r tumour dose } \\
\text { Total removal, } 4,000 \mathrm{r} \text { tumour dose } \\
\text { Biopsy, } 8,600 \mathrm{r} \text { tumour dose }\end{array}$ \\
\hline Sacrococcygeal & $\begin{array}{l}3 \mathrm{yr}^{2} \\
5 \mathrm{yr}^{1} \\
2 \mathrm{yr}^{1} \\
7 \mathrm{yr}^{1} \\
5 \mathrm{yr} .\end{array}$ & $\begin{array}{l}2 \text { yr. } \\
4 \text { yr. } \\
1 \text { yr. } \\
5 \text { yr. } \\
2 \text { yr. }\end{array}$ & $\begin{array}{l}\text { Total removal, radiation (dose unknown) } \\
\text { Subtotal removal } \\
\text { Total removal } \\
\text { Biopsy, 6,100r tumour dose } \\
\text { Biopsy, radiation (dose unknown) }\end{array}$ \\
\hline
\end{tabular}

'Patient alive or was alive when lost to follow-up.

\section{TABLE III}

PREDOMINANT PRESENTING SYMPTOMS OF INTRACRANIAL CHORDOMA

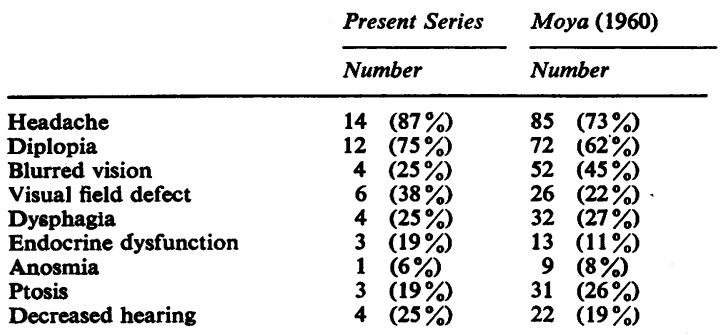

Although it was rare for a patient to report a visual field defect, the latter was often found on testing. The development of headaches and visual disturbance usually paralleled each other in onset and progression. Additional symptoms reported in order of decreasing frequency were dysphagia, decreased hearing, endocrine disturbance manifested by impotence in the male and amenorrhea in the female, and anosmia.

As to signs, $90 \%$ of our patients had an extraocular palsy, most often due to sixth nerve involve- ment. Decreased visual acuity was present in $50 \%$ and visual field abnormalities in $25 \%$ of patients, one-fourth being blind in one eye. Additional findings in some cases were unilateral involvement of some of cranial nerves 8 through 12, as demonstrated in $40 \%$ of patients. When most of the lower cranial nerves were affected, evidence of involvement $\overrightarrow{\overline{0}}$ of long tracts as indicated by a contralateral hyperreflexia, mild hemiparesis, and a positive sign of Babinski, could also be found.

A retropharygeal mass was present in five of $15 \overline{5}$ intracranial cases and an intranasal mass in one, 0 occasionally leading to difficulty in breathing or윽 swallowing. These masses, however, were often? asymptomatic and were first seen on radiographs, biopsy resulting in a positive diagnosis.

Laboratory studies were normal except for윽 marginal elevation of the cerebrospinal fluid $>$ protein in five patients. Values above $100 \mathrm{mg} . \%$ were not observed. Minimal elevation of cerebrospinal fluid pressure was present in only two cases. Tests of adrenal and thyroid function in one patient ${ }_{0}^{N}$ having amenorrhea were normal.

Radiography revealed destruction of bone in theo region of the sella turcica in 13 of the 16 patientso 


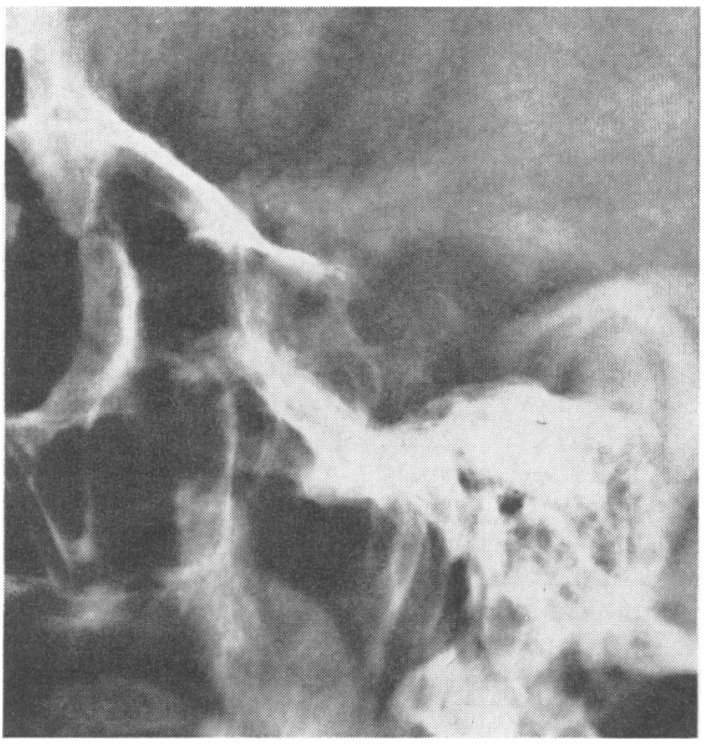

FIG. 1. Radiograph of a 60-year-old man with diplopia for two years and involvement of cranial nerves 2 through 7 . Diagnosis was established by sphenoid sinus biopsy. The radiograph demonstrates erosion of the dorsum sellae and clivus and an intrasphenoid sinus mass.

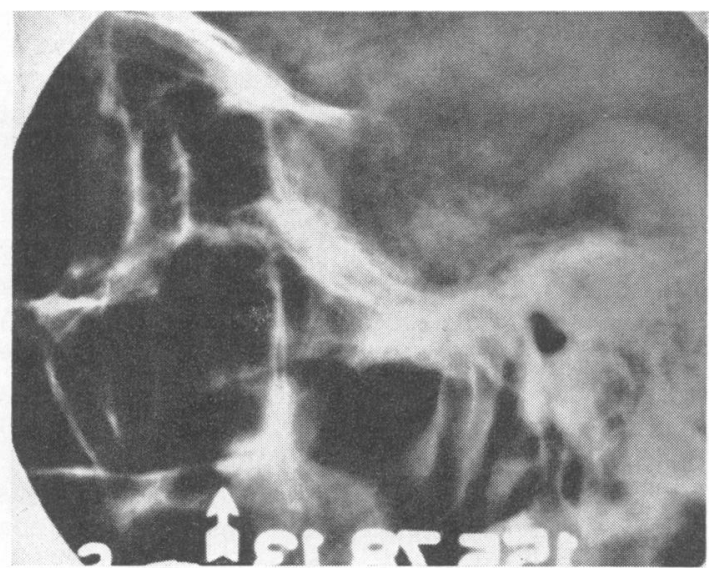

FIG. 2. Same patient as in Figure 1. This radiograph, taken one year later after 5,000r radiotherapy to the sella region, demonstrates progression of the tumour. The posterior clinoids and sella turcica are eroded as well as the dorsum and clivus. with intracranial lesions (Figs. 1 and 2). In 10 cases, destruction and infiltration of the sphenoid bone and sinus were noted. Destruction of the clinoid processes was present in nine patients and of the petrous ridge in three. Suprasellar calcification was observed in $30 \%$ of cases.

Contrast studies such as arteriography or air encephalography always revealed superior and posterior displacement of the third ventricle and aqueduct, while some degree of aqueductal obstruction was often present leading to slight dilatation of the third and lateral ventricles (Fig. 3). No patients

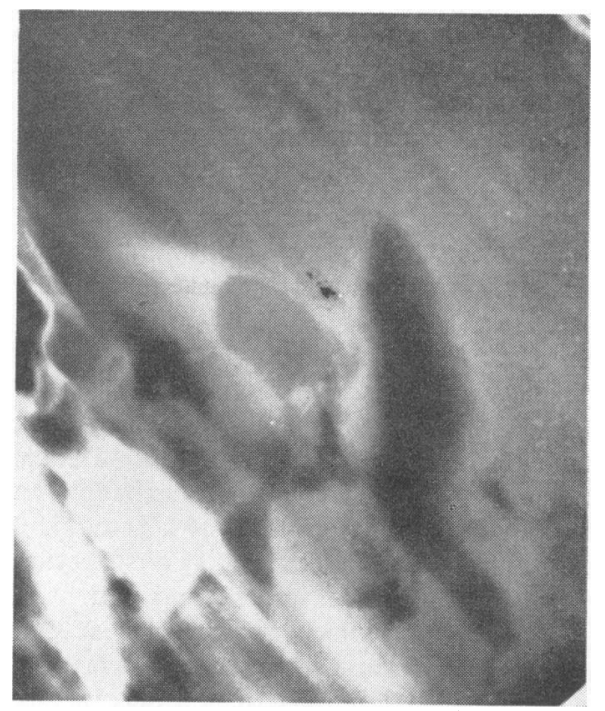

FIG. 3. Radiograph of a 49-year-old man with symptoms for seven months, disturbance of cranial nerves 8 through 12 on the left, and a nasopharyngeal mass. Autotomograph during pneumoencephalography shows posterior and superior displacement of the third ventricle, aqueduct of Sylvius, and fourth ventricle. Also the clivus is destroyed.

in this series, however, had sufficient aqueductal blockage to cause papilloedema even though the chiasmal and interpeduncular cisterns were usually obliterated. Superior and lateral displacement of the supraclinoid portion of the internal carotid artery and of the anterior and middle cerebral arteries was often present. No tumour stains or abnormal vessels were seen. In a word, extensive suprasellar, parasellar, and often intrasellar tumour masses could be demonstrated by appropriate contrast studies.

Eleven patients had been closely followed for longer than one year. In seven symptoms had progressed within this period following therapy. The 
average time until evidence of recurrence was 11 months. In our total series of intracranial chordoma, the average time of survival at this time was 43 months (3.6 years) following surgical and/or radiation therapy, or 56 months ( 4.7 years) from the onset of symptoms. In contrast, in untreated intracranial chordoma, the average survival time from onset of symptons was 28.8 months (Mabrey, 1935). Of the 16 patients in this series, six were able to return to normal activities in school or work after initial treatment, although at this time no patient is thought to be free of tumour.

CERVICAL All four patients noted pain as their initial symptom. In three the pain was localized to the posterior neck, and in the fourth, the initial pain was in the mastoid region. Further progress of the disease resulted in increasing pain spreading to the arms and shoulders in two patients and the appearance of a mass in the other two patients. The masses were retropharyngeal in one patient and 'pre-auricular' in the other. Generally, symptoms were present for one year before admission to hospital was advised.

On examination, three of the four patients had palpable masses, one being an asymptomatic retropharyngeal mass. Two patients demonstrated long tract signs with weakness and decreased sensation in the lower extremities. Laboratory studies were normal except for a markedly elevated cerebrospinal fluid protein level of $260 \mathrm{mg} . \%$ in the patient with severe lower extremity dysfunction and a slight protein elevation in a second patient.

Radiography revealed pharyngeal soft tissue masses in three patients. Bony erosion was noted in two patients with collapse of the second cervical body in one. The bony lesions were found in the high cervical region, above the fourth cervical body. Myelography was performed on only one patient in whom a partial block was demonstrated by lumbar puncture.

Symptoms recurred within one year in $75 \%$ of these patients. The average time of survival, regard-' less of method of treatment, was seven years from the time of diagnosis and treatment and eight years from the onset of symptoms (Table II). In general, the greater the degree of spinal cord involvement, the shorter the prognosis. When marked long tract signs were present, total incapacitation and death occurred within one year. No confirmed cure of such lesions at this site has been reported.

THORACIC There was only one patient with a lesion at the thoracic level in our series and indeed, tumours of this region have been rare. The presenting symptom was local pain. A radicular component was noted when root encroachment later occurred.
Two years elapsed between onset of symptoms and $\stackrel{\mathbb{Q}}{=}$ therapy of this tumour and this time lag appears consistent with reports in the literature (Rosenqvist and Saltzman, 1959). Other symptoms which these authors reported included decreased sensation and w strength in the lower extremities, while examina- $\frac{O}{5}$ tion usually revealed long tract signs with pathological reflexes and motor and sensory impairment $₹$ below the lesion. Laboratory studies were reported as normal except for elevation of the cerebrospinal $\stackrel{\text { ? }}{?}$ fluid protein which, in our patient, was $594 \mathrm{mg} . \%$ 을 associated with a complete cerebrospinal fluid 음 block. This is again consistent with reports in $\frac{\bar{m}}{7}$ the literature, as partial or complete block was $\stackrel{\mathbb{\Omega}}{\Omega}$ usually found by the time the patient was first admitted to hospital. Radiography in our patient $\overrightarrow{.}$ revealed increased density of the involved vertebra, without collapse, and definition of a soft tissue mass. $\overrightarrow{\vec{\omega}}$ Vertebral collapse and osteolytic lesions are, $\stackrel{\circ}{\circ}$ however, as frequently present as are the findings $\overline{\overline{ }}$ just described (Windeyer, 1959).

Since this tumour cannot be completely removed, the time of recurrence will depend mainly on the $i$ major direction of growth of the tumour. In our case, $\vec{G}$ the patient was well and at work for two years following decompressive laminectomy and radiation $\frac{}{5}$ therapy (Table II). He was then lost to follow-up. $\overrightarrow{7}$ general, the lesion will be fatal within six years of the onset of symptoms (Baker and Coley, 1953).

LUMBar Pain was the presenting symptom in four cases of lumbar involvement in our series. This symptom was present as long as six years in one patient and four years in a second before the $\bar{\partial}$ definitive diagnosis was established. Later symptoms were those of cauda equina compression or nerve $\stackrel{D}{\Phi}$ root irritation. Two patients presented with urinary incontinence and decreased sensation and weakness of the legs. The other two patients had a clinical history suggestive of a herniated nucleus pulposus with shooting pains in a lower lumbar dermatomal distribution and appropriate weakness and sensory impairment. Examination was compatible with a cauda equina syndrome with decreased deep tendon 3 reflexes and impairment of sensation. Laboratory studies were normal except for minimal elevations in the cerebrospinal fluid protein to 50 to $60 \mathrm{mg} . \%$ in the two patients with signs of limited root irritation. $\frac{}{5}$ Marked elevation of cerebrospinal fluid protein was $>$ present in the two patients having signs of cauda equina compression.

Radiography revealed pedicle erosion and widen-ing of intervertebral foramina in two patients, collapse of a vertebral body in one, and increased $\omega$ bone density with some radiolucent areas in the last. Similar changes have been previously described 
in the literature (Allen, 1955; Sennett, 1953; Windeyer, 1959).

Recurrence of tumour was noticed in all patients within one year of combined operative and radiation therapy. Though one patient has been symptom free for seven years following a second course of radiotherapy, it is doubtful if any is free of tumour. Survival has been reported to be less than six years from the onset of symptoms (Baker and Coley, 1953). To this time, average survival has been seven years from the onset of symptoms and four years from the time of initial diagnosis and therapy in this group of patients, of whom one died 4.5 years after the onset of symptoms and only one is back at work (Table II).

SACROCOCCYGEAL Pain in the rectum was the presenting symptom in four of five patients with sacrococcygeal chordoma. This was present for six months to one year before hospital admission and diagnosis. In the fifth patient, an asymptomatic posterior sacral mass was present for three years before diagnosis and therapy. Additional symptoms

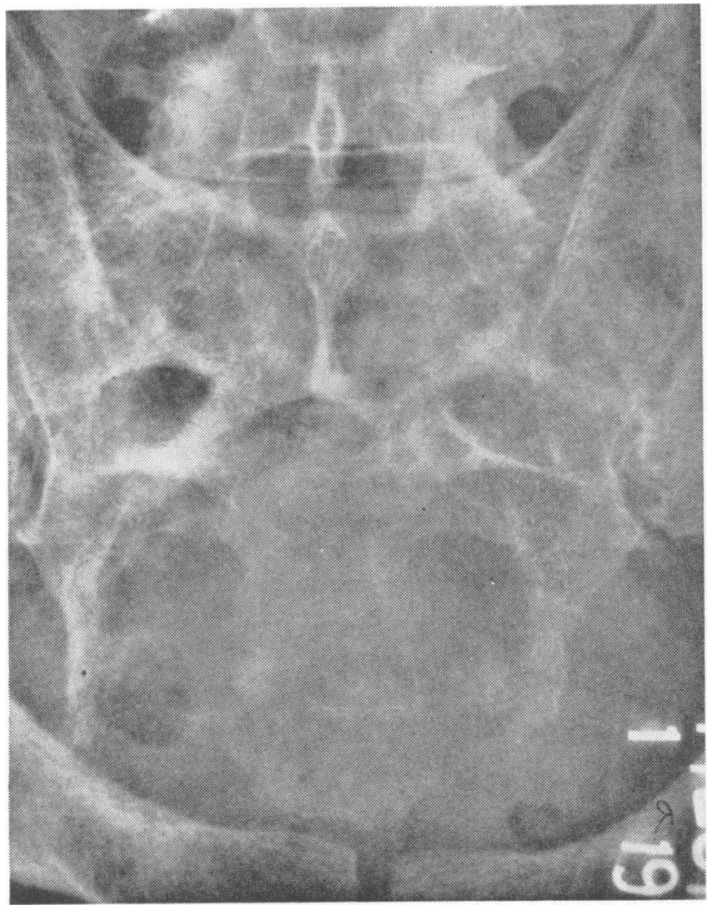

FIG. 4. Radiograph of a 54-year-old man with pain in the sacrum for one and a half years. A rectal mass was present. The radiograph demonstrates expansion of the sacrum with destruction and rarefaction of bone. noted in all patients before admission to hospital were perirectal, buttock, or thigh pain, or disturbed sensation and sphincter disturbance, usually constipation and/or incontinence. On examination, all patients had a retro-rectal mass which lay beneath the rectal mucosa but did not penetrate it. In addition, two patients had saddle anaesthesia. Laboratory studies were always reported within normal limits.

Radiography revealed destructive or radiolucent areas in the sacrum and coccyx (Fig. 4). No osteoblastic areas were noted nor was widening of the spinal canal observed (Hsieh and Hsieh, 1936). Barium enema examination showed the rectum and sigmoid colon to be displaced anteriorly.

The tumour recurred after therapy within one year in four of five cases. The average survival time from onset of symptoms has been five years; survival from time of therapy has been three years (Table II). Survival from the time of onset of symptoms has been reported to be one to six years but survival for longer periods has not been unusual (Faust et al., 1944). Only one patient has returned to work following therapy of such tumours at this site.

\section{DIAGNOSIS}

The diagnosis of chordoma can rarely be made on clinical grounds alone. By combining the clinical picture with radiographic findings, however, a diagnosis of chordoma may be strongly suspected.

The intracranial chordomata can be divided clinically into two groups: those in a parasellar location affecting cranial nerves 1 through 7 and those chordomas of the clivus which involve the eighth through twelfth cranial nerves and often the upper cervical spinal cord. Cases of the former group generally present with a triad of headache, visual disturbances, and diplopia (Givner, 1945; Meaney, Greenwald and Phalen, 1956; Moya, 1960). Givner (1945) states: 'Unexplained paralysis of the lateral rectus muscle ... in a patient in his thirties with progression to chiasmal signs, headaches preceding defects of the visual fields and no evidence of disorder of the pituitary should suggest chordoma'.

Symptoms of impotence, loss of libido, or disordered menstruation were present in 10 to $20 \%$ of cases. Papilloedema and optic atrophy are seen with equal frequency, being present in $20 \%$ of cases (Givner, 1945). No patient in our series presented with papilloedema although four had optic atrophy.

On radiographic examination, erosion of the clinoid processes, destruction of the sphenoid wing, and enlargement of the sella turcica were most often seen with destruction of some part of the sella in $70 \%$ 
of cases (Utne and Pugh, 1955). Suprasellar calcification is present in from 30 to $75 \%$ of cases (Halper, 1949; Moya, 1960; Wood and Himadi, 1950). If sphenoid sinus involvement was present, biopsy of the sinus usually led to a positive diagnosis (Dahlin and MacCarty, 1952).

Of the special radiographic studies, gas encephalography generally proved more helpful than arteriography since these tumours arise from the midline. Gas encephalography will demonstrate posterior and superior displacement of the aqueduct and third ventricle with non-filling of the anterior portion of the third ventricle (Utne and Pugh, 1955; Wood and Himadi, 1950). This was found in all of our gas encephalograms and in $90 \%$ of those reported by Moya (1960). In addition, ventricular dilatation was present in $20 \%$ of the patients studied.

In the predominately clivus chordoma, presenting symptoms were those of a tumour of the cerebellopontine angle, some cases also having cervical spinal cord involvement. Decreased hearing, dysphagia, tongue deviation, and neck pain were common presenting symptoms. In our series, a pharyngeal mass, most often symptomatic, was present in $65 \%$ of patients with lower cranial nerve signs. Such a mass should always be sought in the presence of lower cranial nerve dysfunction. If a mass can be seen, persistent attempts at biopsy will usually result in a positive tissue diagnosis. It was our experience that several attempts at biopsy were often necessary as the tumour does not invade the mucosa but lies deep in the pharyngeal wall, pushing normal structures before it as it grows out from the cervical spine. On radiographic examination, destruction of the clivus and a soft tissue retropharyngeal mass were often seen (Windeyer, 1959; Wood and Himadi, 1950). Involvement of the upper cervical vertebrae was not rare, making it difficult to decide whether a predominantly cervical or intracranial tumour was present.

The differential diagnosis, of course, depends on the location of the tumour. One must consider chromophobe adenoma, craniopharyngioma, suprasellar or clivus meningioma, neurinoma, and nasopharyngeal carcinoma. Except for the last named neoplasm, extracranial extension of the tumour will aid in ruling out the other lesions.

In cervical chordomas, findings are those of a pharyngeal mass and/or of cervical spinal cord compression. All of our patients presented with neck pain and three of four with a palpable mass in the neck. The combination of dysphagia and cervical pain should suggest the diagnosis (Toole and Ioannovich, 1960). On radiographs, one sees an irregular lytic lesion of the involved bodies with preservation of the disc space. A soft tissue mass is usually present. The differential diagnosis musto include metastatic tumour, tuberculous osteo- $\frac{-}{0}$ myelitis and abscess, neurofibroma and meningioma (Sennett, 1953).

The thoracic chordoma is unlikely to give any specific signs clinically or radiologically of its? identity. Symptoms of spinal cord compression, such as pain, lower extremity weakness, and sphincter disturbance, are seen. Radiological examination shows an osteolytic lesion with an adjacent soft tissue mass. If no soft tissue mass is present $\vec{\nabla}$ the radiological appearance of the vertebra mayo

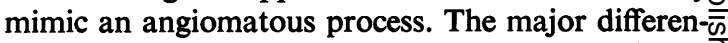
tial diagnoses are metastatic tumour, haemangioma,,$\widehat{D}$ myeloma, chondroma, and giant cell tumour (Sennett, 1953).

Lumbar chordomas demonstrate clinical and $\overrightarrow{0}$ radiographic findings identical with those of the thoracic group (Baker and Coley, 1953; Morris andw Rabinovitch, 1947; Sennett, 1953). Though neither the lumbar nor thoracic areas are common sites for chordoma, the former site is involved twice asi frequently as the latter.

Sacrococcygeal chordoma will present with painor a mass, usually both being present. If a sacraK mass presents posteriorly, however, no pain will be felt. Disturbance of sphincter control, most of tonconstipation, is also common. In our series, alp patients presented with pain, sphincter disturbange and a palpable retro-rectal mass. Twenty-nine of 32 patients presented with pain and $50 \%$ with eithefas mass or sphincter disturbance in the series of Dahlin and MacCarty (1952). Other symptoms ob weakness, paraesthesias, and numbness were less constant, being present in less than $20 \%$ of patients On examination, the most constant finding is a masळ (Dahlin and MacCarty, 1952; Gentil and Coley? 1948). When the mass presents anteriorly, it mays displace the rectum or bladder, although invasion of the mucosa of these organs has not yet been reported Other findings are related to the degree of nerve root involvement found. This tumour has beets reported in patients as young as 2 years (Mont $\overline{0}$ gomery and Wolman, 1933). In Mabrey's (1935 collected series of 85 sacrococcygeal chordomas $\frac{3}{5}$. four patients were below the age of 9 years.

The distinctive radiological findings of sacro coccygeal chordoma have been described by Hsieh and Hsieh (1936). These are expansion of the sacrum in which it appears widened in one or more diameters; rarefaction or destruction of bone $\frac{i}{\dot{*}}$ trabeculation; and calcifications. Erosion of bon $\otimes$ was found on radiographs in $80 \%$ of our cases Previous studies have noted osteolytic lesions in at least $75 \%$ of patients (Utne and Pugh, 1955).

The differential diagnosis of this tumour includes 
all of the presacral tumours (Castro, 1961). Of those causing pain, bone erosion, and a palpable mass, the most common lesions are metastatic tumour, sarcoma, tuberculous osteomyelitis, bone tumours, and anterior meningocoeles. On histological study of the removed tumour, mucoid carcinoma of the rectum or sigmoid has been reported as frequently being misdiagnosed as chordoma. We have a further tumour, a hypernephroma, which was repeatedly diagnosed as chordoma until necropsy revealed its true origin. This tumour presented in the lumbosacral region and exhibited all of the clinical and radiographic characteristics of chordoma. Two laminectomies were performed, adequate pathological specimens being taken each time. A diagnosis of chordoma as thought to be represented by a typical histological picture was returned on both occasions. Thus, we must caution against confusing hypernephroma as well as mucoid carcinoma with chordoma.

\section{PATHOLOGY}

The microscopic recognition of chordoma is sufficiently well known not to demand discussion here. A description of macroscopic pathology encountered at operation, however, is essential in order to evaluate the modes of treatment offered for this tumour.

There has not been a case reported of total removal of an intracranial chordoma. Embryological studies of the notochord in the base of the skull have demonstrated that the notochord traverses bony structures to lie both on the dorsum sellae intracranially and against the basilar portion of the occipital bone extracranially (Gardner and Turner, 1941; Sensenig, 1956). Neoplastic change of the notochord thus gives rise to a midline tumour which may grow up into the base of the brain or down into the sphenoid sinus or into the nasopharynx. The tumour is unencapsulated or has a pseudo-capsule and invades both dura and bone with facility.

When seen at operation, the tumour has usually grown more to one side than another causing predominately unilateral symptoms. Rather than presenting as a single large mass, several lobules of tumour connected by small bridges of tumour tissue are seen. The basilar cisterns are collapsed by the upward growth of the tumour and the third ventricle, pons, and aqueduct are pushed upward and backward. Thus, hydrocephalus is most often due to a combination of aqueductal compression and collapsing of the basilar absorbing surfaces making external decompression the only means of achieving reduction of increased intracranial pressure.

Since the intracranial portion of the chordoma starts at the dorsum sellae, it may follow a pathway of growth predominately into the middle and anterior fossae or into the posterior fossa. Anterior growth will cause dysfunction of the hypophysis and upper cranial nerves by direct tumour growth to and around these structures. Posterior growth will mainly affect the lower cranial nerves.

It has previously been noted that most patients with intracranial chordoma have a sixth nerve palsy (Givner, 1945). The reason for this is evident when one considers that the sixth nerve must course over the greatest bulk of the tumour to reach its foramen of exit.

At necropsy, the tumour is seen to grow as a sheet of cells over the floor of the middle or posterior fossa with many large lobules arising from this sheet. The tumour is noted to surround completely nerve and vascular structures rather than push them aside. Thus, anteriorly, the intracranial carotid artery is buried within the tumour while the cavernous sinus, being a more rigid structure, is invaded by tumour. When removal of the tumour is attempted, parts of it are found to be soft and to yield to suction easily; other parts are highly vascular or solid and are not amenable to this form of removal.

The chordoma often has a massive retropharyngeal component and when first seen appears to be a tumour only of the nasopharynx. The tumour, however, when traced posteriorly will be seen to arise from the base of the skull or the cervical vertebrae. At the time of necropsy, an intracranial or intraspinal extension of the tumour is always noted. Thus, total removal of these nasopharyngeal chordomas is impossible.

In the vertebral region, the chordoma surrounds the spinal cord, resembling a metastatic tumour, and causes compression within the bony canal. The tumour's growth, however, may be as extensive anteriorly into the retropleural or retroperitoneal space as it is posteriorly. Our series included several cases in which the surgeon believed that total removal of the tumour had been accomplished only to find recurrence within one year. This is understandable in the light of the gross pathology. Since whatever notochordal remnants the chordoma arises from are present within the body of the vertebra or disc, rather than external to them, it is evident that simple removal of tumour from around the spinal dura cannot effect total removal.

At necropsy, the chordoma can be seen infiltrating the vertebral body and growing anteriorly into the paraspinal tissues or posteriorly to surround the spinal cord. Once within the spinal canal, growth up or down the canal may occur.

The pathological findings in the sacrococcygeal chordoma present a separate problem from those 
encountered elsewhere in the skeletal axis. The tumour arises from the lower bony sacrum and grows out freely beneath the skin posteriorly or below the peritoneal reflection anteriorly. Since removal of the locally involved structures can be accomplished without danger to life, radical excision of the sacrum, coccyx, and adjacent soft tissue structures can be attempted. Both at operation and at necropsy, however, sheets of tumour cells are often seen growing a considerable distance rostrally in the sacral canal. This must be carefully watched for, since these cells can easily escape notice and yet form a nidus for a rapid recurrence of tumour.

Attempts at discrete removal of extradural tumour alone must be unsuccessful because of the constant infiltration of the tumour into the sacrum. A punched-out area composed solely of fragmented bone and tumour will usually be found within the sacrum. Thus, because its location allows radical excision, sacrococcygeal chordoma is the only type that may be removed totally.

Another facet of chordoma growth is the presence of metastases. Though metastases occur not infrequently from sacrococcygeal chordoma, there are isolated reports of metastases from other parts of the neuraxis (Faust et al., 1544; Gentil and Coley, 1948; Graf, 1944; Greenwald, Meaney, and Hughes, 1957; Güthert and Henkel, 1941; Mabrey, 1935; Maynard, 1953; Morris and Rabinovitch, 1947; Schneegans and Mandigas, 1938; Toole and Ioannovich, 1960; Uhr and Churg, 1949). Spread from the sacrococcygeal region has been reported to the peritoneum, lymph nodes, liver, lung, and pleura. Of the seven reported cases of metastases from chordoma outside of the sacrococcygeal region, two have been from intracranial chordoma, both spreading to the lung but one to the heart as well, one from the cervical region to the lung, one from the thoracic region to the lung, and three from the lumbar region. Spread from the lumbar region has been to the lung and in one case to the brain and pancreas as well.

Three patients in our series demonstrated metastases, one each from intracranial, cervical, and sacrococcygeal locations. In the first two cases, metastases were to the lung only whereas the sacrococcygeal tumour spread to the liver, lymph nodes, skin, and lung. It is of interest that the patients with intracranial and cervical chordomas survived 15 and nine years respectively and both received radiotherapy in excess of $10,000 \mathrm{r}$ tumour dose. The patient with a sacrococcygeal chordoma received $6,100 \mathrm{r}$ tumour dose and survived for seven years. That the two factors of long survival and massive radiation may have enhanced tumour spread must be considered.
MANAGEMENT

With the realization that total removal of a chordomas cannot be performed except occassionally in theo sacrococcygeal region, therapy must be directed 0 toward surgical decompression of vital structures followed by radiation (Dahlin and MacCarty, 1952; Hass, 1934; Rosenqvist and Saltzman, 1959 Sennett, 1953). Radiotherapy is administered as. palliation and can result in regression of tumour and relief of pain.

An evaluation of different methods of therapy inc the largest series of patients treated at one institution $\overline{\bar{N}}$ concludes that a combination of surgery and radiotherapy offers the best chance of prolonging survivalo (Dahlin and MacCarty, 1952). Unfortunately, the number of patients in each therapeutic category is $\overrightarrow{0}$ too small to indicate anything more than a trend.

Analysis of the rationale for surgical intervention must again be separated into the intracranial and vertebral groups. In intracranial tumours, if as diagnosis can be established by pharyngeal oru sphenoid sinus biopsy, operation would be indicated only for decompression of the optic nerves whenblindness is threatened or for performance of an external shunting procedure for relief of hydro-윽 cephalus. If the diagnosis has not yet been establishedpre-operatively, some operative procedure to ascerr $\frac{D}{2}$ tain the diagnosis would be indicated.

In the vertebral regions, rapidly impending par $\overrightarrow{\vec{\theta}}$ plegia would constitute the only indication surgical intervention other than for biopsy purposes though biopsy alone could probably be performedo by percutaneous biopsy of the involved vertebra. At post-mortem examination in a case of cervicap chordoma, we noted focal areas of degeneration in the lateral and posterior columns though actual cord? compression was not marked. This was presumably $\overrightarrow{0}$ the effect of vascular compromise and the though $B$ that operation may accomplish only further de? crease of an already marginal blood supply must be kept in mind.

One series of 18 patients with radical sacrectomyठ for sacrococcygeal chordoma has already beeri reported (MacCarty, Waugh, Coventry, and. O'Sullivan, 1961). In a follow-up period of as long as 12 years, but averaging six years, 12 patients are still alive, seven without recurrence. In addition too operation, 13 patients received post-operative radiotherapy. No report has been made on post operative morbidity but of the first eight patients reported, only one was noted to have returned to work (MacCarty, Waugh, Mayo, and Coventry N 1952).

In our patients, the dose of radiation has beensteadily increased over the years so that a 3,000 t\& 
5,000 r tumour dose will be given as the initial treatment dose and doses of 2,000 to 3,000r tumour dose repeated as often as recurrence is noted (Table II). It is our feeling that tumour doses greater than $5,000 \mathrm{r}$ cause more prolonged remission than smaller doses. This trend toward higher radiation doses is noted in the literature also. Ormerod (1960) reported a case of intracranial chordoma receiving $6,175 \mathrm{r}$ tumour dose with radiographic evidence of disappearance of tumour. Tumour reappeared on the opposite side in one and a quarter years and was treated with 4,175 r tumour dose with disappearance of the second tumour. The patient was well without recurrence four years later. Friedman (1953) has treated a lumbar chordoma with $7,200 \mathrm{r}$ tumour dose by rotational methods and has noted no recurrence in one year.

Other methods of treatment reported in the literature have been intracranial implantation of irradiated materials and chemotherapy (McSweeney and Sholl, 1959; Zoltán and Fényes, 1960). In two of our patients, intracarotid perfusion of the chemotherapeutic agent, methotrexate, was followed by death in eight days in one patient and evidence of recurrence of tumour in the other patient within one year.

At present, our plan of therapy consists of establishment of diagnosis by the simplest means of biopsy followed by large radiation doses to the tumour, 5,000r tumour dose or greater. We reserve surgical therapy only for acute problems which may be handled in no other way. This means of therapy has not been followed for sufficient time to evaluate its benefits.

\section{CONCLUSIONS}

Thirty cases of chordoma seen at the Columbia Presbyterian Medical Centre since 1927 are reviewed and a rationale for treatment offered. Sacrococcygeal chordoma is the only type amenable to complete excision and thus should be treated surgically. Cases of intracranial and vertebral chordoma should be biopsied by closed or open methods for confirmation of diagnosis, then given large tumour doses of therapeutic radiotherapy. Except for emergency situations demanding surgical decompression for the preservation of life or of vital structures, surgical treatment of non-sacrococcygeal chordoma has little to offer.

\section{REFERENCES}

Allen, A. L. (1955). Clin. Orthop., 6, 158.

Baker, H. W., and Coley, B. L. (1953). J. Bone. Jt Surg., 35, 403.

Castro, A. F. (1961). Stn. med. J. (Bgham, Ala.), 54, 969.

Congdon, C. C. (1952). Amer. J. Path., 28, 793.

Dahlin, D. C., and MacCarty, C. S. (1952). Cancer (Philad.), 5, 1170.

Faust, D. B., Gilmore, H. R., and Mudgett, C. D. (1944). Ann. intern. Med., 21, 678.

Forti, E., and Venturini, G. (1960). Riv. Anat. pat., 17, 317.

Friedman, M. (1953). Bull. Hosp. Jt Dis. (N.Y.), 14, 180.

Gardner, W. J., and Turner, O. (1941). Arch. Surg., 42, 411.

Gentil, F., and Coley, B. L. (1948). Ann. Surg., 127, 432

Givner, I. (1945). Arch. Ophthal., 33, 397.

Graf, L. (1944). Arch. Path., 37, 136.

Greenwald, C. M., Meaney, T. F., and Hughes, C. R. (1957). J. Amer. med. Ass., 163, 1240.

Güthert, H., and Henkel, H. (1941). Zbl. allg. Path. path. Anat., 77, 376.

Halper, H. (1949). Brit. J. Radiol., 22, 88.

Hass, G. M. (1934). Arch. Neurol. Psychiat. (Chic.), 32, 300.

Hsieh, C. K., and Hiesh, H. H. (1936). Radiology, 27, 101.

Mabrey, R. E. (1935). Amer. J. Cancer., 25, 501.

MacCarty, C. S., Waugh, J. M., Mayo, C. W., and Coventry, M. B. (1952). Proc. Mayo Clin., 27, 73. Gynec. Obstet., 113, 551 .

Maynard, R. B. (1953). Aust. N.Z.J. Surg., 22, 215.

McSweeney, A. J., and Sholl, P. R. (1959). Arch. Surg., 79, 152.

Meaney, T. F., Greenwald, C. M., and Phalen, G. S. (1956). Clin. Orthop., 7, 103.

Montgomery, A. H., and Wolman, I. J. (1933). Amer. J. Dis. Child., 46, 1263.

Morris, A. A., and Rabinovitch, R. (1947). Arch. Neurol. Psvchiat. (Chic.), 57, 547.

Moya, G. (1960). Encéphale, 49, 495.

Ormerod, R. (1960). J. Laryng., 74, 245.

Poppen, J. L., and King, A. B. (1952). J. Neurosurg., 9, 139.

Rosenqvist, H., and Saltzman, G. F. (1959). Acta radiol. (Stockh.), $52,177$.

Schneegans, E., and Mandigas, (1938). Bull. Soc. Pédiat. Paris, 36, 535.

Sensenig, E. C. (1956). Amer. J. Anat., 98, 357.

Sennett, E. J. (1953). Amer. J. Roentgenol., 69, 613.

Toole, H., and Ioannovich, D. (1960). Arch. Otolaryng., 72, 219.

Uhr, N., and Churg, J. (1949). Ann. intern. Med., 31, 681.

Utne, J. R., and Pugh, D. G. (1955). Amer. J. Roentgenol., 74, 593.

Windeyer, B. W. (1959). Proc. roy. Soc. Med., 52, 1088.

Wood, E. H., and Himadi, G. M. (1950). Radiology, 54, 706.

Zoltán, L., and Fényes, I. (1960). J. Neurosurg., 17, 888. 